\title{
CONTENT OF $\beta$-GLUCANS IN OAT GRAIN AS A PERSPECTIVE DIRECTION OF BREEDING FOR HEALTH PRODUCTS AND FODDER
} (review)

\section{I.G. LOSKUTOV1, 2 , V.I. POLONSKIY 3}

\author{
${ }^{1}$ Federal Research Center N.I. Vavilov All-Russian Institute of Plant Genetic Resources, Federal Agency of Scientific \\ Organizations, 42-44, ul. Bol'shaya Morskaya, St. Petersburg, 190000 Russia, e-mail i.loskutov@vir.nw.ru (corre- \\ sponding author); \\ ${ }_{2}^{2}$ Saint-Petersburg State University, 7-9, Universitetskaya nab., Petersburg, 199034 Russia; \\ ${ }_{3}^{3}$ Krasnoyarsk State Agrarian University, 90, pr. Mira, Krasnoyarsk, 660049 Russia, e-mail vadim.polonskiy@mail.ru \\ ORCID: Polonskiy V.I. orcid.org/0000-0002-7183-0912 \\ The authors declare no conflict of interests
}

Received June 16, 2016

\begin{abstract}
The paper offers a review of the published data on the structure of $\beta$-glucan molecules in the oat kernel, their influence on the lipoprotein content and glycemic index, on the digestive system operation and cancer cells, as well as on other human health indicators. It is noted that watersoluble food fibers have both dietary, prophylactic and healing effects on the human organism (official reports of the US Food and Drug Administration and European Food Safety Association, EFSA). It is discussed that physicochemical properties, chemical modifications and possibilities of industrial application of -glucans define clear perspectives for their potential use in foods, medicinal and cosmetic products. Besides, the results of analyzing the diversity of oat cultivars and species for the $\beta$-glucans content in the kernel are discussed. It is stated that the forms of naked oat have a higher total content of this polysaccharide than the hulled oats, while the latter contain more insoluble $\beta$-glucans in the oat kernel. It should be noted that the content of fibers depends on the meteorological conditions and agricultural methods of oat cultivation. The content of $\beta$-glucans in the kernel is related to the accumulation of protein and fat in the kernel, to the grain volume weight and to grain productivity. The problems of creating new productive oat cultivars with the maximum content and optimal structure of the said polysaccharide combined with other qualitative characters of the kernel, as well as possibilities of producing functional foods from the processed grain of such cultivars are considered. It is concluded that $\beta$-glucans will have an increasing importance in the global food and pharmaceutical industries.
\end{abstract}

Keywords: oat, naked, hulled, Avena, $\beta$-glucans, polysaccharides, food fibers, lipoproteins, glycemic index, cholesterol, cancer cells, breeding, processing

In recent years, in some Western governments, work had been initiated to study barley and oat grains containing $\beta$-glucans, the substances that assist in preventing a number of human diseases. In Russia, only single works are devoted to the study of these chemical compounds in oat grain today. Avena L. genus belongs to the Poacea family and includes more than 20 species, four of which (Avena sativa L., A. byzantina C. Koch, A. strigosa Schreb. and A. abyssinica Hochst.) are cultivated by humans. World collections of Avena species count more than 130 thousand samples, preserved in 63 countries [1]. Common oat (Avena sativa) is the main economically significant cultivated species. According to the world grain harvest ( 24 million tons annually) oats are on the 6th place after wheat, rice, corn, barley and sorghum [2]. Oats are mostly cultivated in Europe, Asia, South America, Australia, and less cultivated in Africa. It occupies the largest areas in Russia, Canada and the USA. This mesophyte agricultural crop is well adapted to a wide range of soils and temperature conditions.

Oat grain has a high nutritional value, contains unsaturated fatty acids, basic mineral elements, globular proteins and $\beta$-glucans (the highest values 
among cereals), characterized by the presence of a variety of chemical substances exhibiting antioxidant properties [3]. Oats are traditionally regarded as a nutritious grain crop, and there is evidence that products derived from it can help in the prevention of certain chronic diseases [4, 5]. Besides, by the EU Regulation $41 / 2009$ oats has recently been included in the number of gluten-free ingredients safe for celiac disease (i.e. chronic intolerance to gluten-forming proteins, which are mainly contained in wheat, rye and barley weevil), provided that the gluten content in the grain should not exceed $20 \mathrm{ppm}$. When studying the biochemical and immunochemical characteristics of 36 cultivars of oats, it was found out that in most samples the content of such proteins was below $20 \mathrm{ppm}$ and only in some cultivars exceeded $80 \mathrm{ppm}[6]$.

Structure of $\beta$-D-glucans. In cereals (unlike most crops), the cell walls of the endosperm of the weevil contain very little count of cellulose and consist mainly of arabinoxylans and $(1,3 ; 1,4)-\beta$-D-glucans, the ratio of which varies significantly in different species: arabinoxylans predominate in rye and wheat, while $(1,3 ; 1,4)-\beta-D$-glucans predominate in barley and oats [7]. The latter are typical for all members of Poacea family. The level of $(1,3 ; 1,4)-\beta-\mathrm{D}-$ glucans varies from 3 to $11 \%$ in barley, riches $1-2 \%$ in rye and is $<1 \%$ in wheat, with only traces manifested in other grains [8]. $(1,3 ; 1,4)-\beta$-D-glucans are water-soluble linear homopolysaccharides whose molecules consist of approximately 2500 residues of $\beta-(1,3)$ - and $\beta-(1,4)$-D-glucopyranose. Most segments in polymer chains are trimers and tetramers [9], usually in the oat grain their molar ratio is 1.5:2.3 [10, 11]. Trisaccharides predominate in soluble $\beta$-glucans [12]. The molar weight of oat $\beta$-glucans is about $500,000 \mathrm{~g} / \mathrm{mole}$ for soluble ones, and less than $200,000 \mathrm{~g} /$ mole for insoluble ones [13]. Recently, a computer 3D model of the $\beta$-glucan molecule has been created. In form, the $\beta$-glucan molecule is an elongated sinuous chain with a pitch of 41.35 E. It is estimated that the rigidity of the chain increases with the increment the proportion of trisaccharides to tetrasaccharides [14].

When dissolved in water, arabinoxylans and $\beta$-glucans, due to their large molecular weight, form hydrocolloids with a high viscosity $[15,16]$. In $\beta$-glucans of oats with a higher tetrasaccharide:trisaccharide ratio, the viscosity of the solutions is higher [17].

The concentration of $\beta$-glucans is measured by chemical and physical methods. According to the international standard, two-stage hydrolysis with lichenase and $\beta$-glucosidase to glucose is used to determine the content of $\beta$ glucans in the oat fraction and groats (Megazyme Inc. test system, USA), the products of which are then recorded spectrophotometrically in the visible spectrum [18]. Recently, a cheaper, modified express micromethod for grain analysis has been developed. By efficiency, when wheat bread, barley flour and oat bran were examined, it was comparable with the standard method [19]. Another physical method is based on measuring the reflection from the ground grain in the near infrared spectrum [20].

Effect of $\beta$-glucans on blood lipoprotein contents. $\beta$-Glucans are dietary fibers, the high-molecular carbohydrates of plant origin, which have a beneficial effect on gastrointestinal tract and systemic processes in human body [21]. $\beta$-Glucans assist in reducing risk of cardiovascular disease [22], maintain or reduce blood cholesterol and the risk of hyperglycemic syndrome [23]. Thus, the hypocholesterolemic effect of $\beta$-glucans of cereals was noted when comparing two diets. The first diet included whole-grain wheat bread, and the second one was enriched with monounsaturated fatty acids and included bread with oat $\beta$ glucan. As a result, total cholesterol was reduced in testers, i.e. blood low density cholesterol decreased in the first group by $16.8 \%$, and in the second group by 
$27.3 \%$. Both diets helped to reduce the overweight, in the second group to a greater extent [24]. In another experiment, the oat diet resulted in a statistically significant decrease in total and low density blood cholesterol, while these indices did not decrease under the corn diet [25].

Glycemia and $\beta$-glucans. Dietary fibers are capable of lowering the glycemic index of food [26]. In glycemia, the dose of an intake of dietary fibers is important for controlling the intake of glucose into the blood and insulin secretion in response to glucose, since in patients with obese, insulin secretion decreased significantly in response to the intake of $3.8 \mathrm{~g}$ of oat $\beta$-glucans [27]. Oat $\beta$-glucans, interacting with other carbohydrates, affect their accessibility and, as a consequence, reduce the glycemic reaction. Thus, for certain ratios of $\beta$-glucans and starch in the diet, the accessibility of starch decreases and the intake of glucose into the blood decreases. What is more, the effect manifested itself more strongly with a higher ratio of these components in the diet [28]. In experiments on mice and in vitro culture, it has been shown that oat $\beta$-glucans are able to regulate glucose metabolism, acting as a potential inhibitor of $\beta$ glucosidase, which can effectively improve the gastrointestinal tract state [29].

A meta-analysis of the articles describing 126 clinical cases demonstrated a significant inverse relationship between the content of total cholesterol, low density lipoproteins, increased high density cholesterol on the one hand, and the use of $\beta$-glucans on the other hand. At the same time, the influence of $\beta$-glucans on the decrease in glucose concentration is not strictly proven and requires longer clinical studies [30]. The ability to reduce the glycemic index is associated with the viscosity of $\beta$-glucans, which determines their functional and physiological effects [31]. As to the normalization of cholesterol, the role of viscosity of $\beta$-glucans is often confirmed no more than indirectly, and the result is not always statistically significant. It is suggested that the different efficacy of $\beta$-glucans may be partly explained by a change in their properties, depending on the diet and dose [32].

The effect of $\beta$-glucans on other indicators of human health. The addition of dietary fibers prolongs the feeling of satiety [33]. The possibility of using $\beta$-glucans in oncology is being intensively studied. The antitumor activity of low-molecular $\beta$-glucans from oat grain was studied on cancerous cells Me45 and A431. The polysaccharide significantly reduced their viability without being toxic to normal HaCaT cells. Increasing the duration of incubation and concentration of $\beta$-glucans significantly enhanced the effect. Immunocytochemically, it has been shown that $\beta$-glucans induce the expression of a specific protein in both cancer cell lines, whereas in normal cells this reaction is significantly lower [34]. $\beta$-Glucans from oat grain had a cytotoxic effect on human melanoma HTB-140 cells. A detailed mechanism for such activity needs further study, but preliminary results are certainly of interest [35].

Low molecular $\beta$-glucans assisted in a decrement of the activity of superoxide dismutase in rats with experimentally induced inflammation of the intestine which received oat $\beta$-glucans of different molecular weights. Under oxidative stress, the inclusion of $\beta$-glucans in the diet improved the indices in the spleen. The obtained data allow us to hope for the use of $\beta$-glucan hydrocolloids to create a composition with antioxidant properties [36].

Cereal dietary fibers, that are not digested in the small intestine and function either as a substrate for further intestinal fermentation or as a filler, serve as a means of preventing certain intestinal diseases and possibly to some extent act as a therapeutic agent [37].

Thus, the consumption of oat products helps reduce blood cholesterol level, including low density cholesterol [38, 39], the risk of cardiovascular diseases, improve liver function, and reduce overweight [40]. Water-soluble dietary 
fibers ( $\beta$-glucans) and phenolic alkaloids (avenanthramides) can be included in the daily diet as functional dietary ingredients [41]. However, the oat $\beta$-glucans have also negative properties. It is suggested that by binding iron ions, $\beta$-glucans may decrease its bioavailability [42]. In addition, the nutritional value of oats for non-ruminant animals is negatively correlated with the content of dietary fibers in the grain [43].

Screening of the cultivars and varieties of oats according to the content of $\beta$-glucans. For many decades, selection for high productivity and plant resistance to stress factors has led to a certain decrease in genetic diversity on quality parameters. Thus, an increase in the number of arabinoxylans and $\beta$-glucans in grain is currently very important. The content and composition of dietary fibers are genetically determined. This means [44] that it is possible to create plant lines with different ratios of $\beta$-glucans and arabinoxylans for the intended use. Thus, a change in the ratio of these components to increase the viscosity index let to get the cultivars for the production of whole grain foods, and its reduction in forage cultivars will prevent negative consequences when feeding poultry and pigs with grain [44]. The study of the content of $\beta$-glucans in oats is associated with its use not only for dietary purposes, but also for the medical industry [45].

A relatively recent identification of genes involved in the biosynthesis of $\beta$-glucans in cereals [15] and the first created genetic map [46] are important steps in the genetic improvement of grain quality and the grain-based food products. The research strategy includes the use of natural genetic diversity and its widening by mutagenesis and transgenesis [47]. The use of mutagenesis to change the content of $\beta$-glucans in the oat grain is described [48, 49]. In the population of 1700 lines of the Belinda cultivar (Sweden), obtained by mutagenesis, forms with high $(>6.7 \%)$ and low $(<3.6 \%)$ content of $\beta$-glucans in the grains were found with a maximum variation of the index from 1.8 to $7.5 \%$, with $4.9 \%$ for the parent [48].

The genetic diversity of oats on grain $\beta$-glucan content was assessed in the framework of two European programs. In the HE-ALTHGRAIN Diversity Screen project (started in 2005 and performed mainly on wheat) in 5 cultivars of oats under the same conditions, the content of $\beta$-glucans and antioxidants in the grains varied significantly [3]. In the next project (the European Project on Avena Genetic Resources for Quality in Human Consumption), the study of 658 cultivars of oats confirmed the contribution of both the genetic and ecological components to the trait expression [50].

It is interesting that many wild species of oats have high grain content of $\beta$-glucans [50], although these studies are very few. The study of a limited set of wild samples, including $A$. sterilis L., revealed an increased (up to $6 \%$ ) amount of $\beta$-glucans in grain of all hexaploid species ( $A$. fatua L., A. occidentalis Durie, A. byzantina) compared to di- and tetraploid species [51-56].

Comparison of the oat collection samples on the content of important biochemical components made it possible to identify the source material of interest for breeding [57]. In the American oat collection, the content of $\beta$-glucans varied from 2.6 to $8.5 \%[58,59]$. In different reports the values were indicated from 1.9 to $7.5 \%$ [8, 60]. In hexaploid oat cultivars from the VIR collection (Russia), the amount of water-soluble polysaccharides varies from 2.58 to $3.52 \%$ [61]. In the Russian-Swedish project (VIR and Nordic Gene Bank, NordGen), the assessment of oat cultivars on the content of $\beta$-glucans revealed the variation from 3.3 to $6.2 \%[62,63]$.

In four oat cultivars grown in 11 different conditions (place and year), the genotype influence on the content of polysaccharides $(23 \%)$ exceeded the 
impact on their molecular weight $(4 \%)$. The external conditions significantly affected the molecular weight of $\beta$-glucans $(71 \%)$ than their content in grain (42\%). A negative correlation was found between the amount of precipitation and the molecular weight of the $\beta$-glucans. At the same time, there is a significant positive relationship between the content of $\beta$-glucans and their molecular weight. Since both these indexes play an important physiological role in digestion, in the authors' opinion, selection for an increased content of $\beta$-glucans is likely to be accompanied by an increase in their molecular weight [64]. Cultivation of 15 samples of Avena sativa and 3 samples of $A$. byzantia revealed significant varietal differences in protein and $\beta$-glucan content, as well as a positive correlation between the grain yield and the content of $\beta$-glucans. The maximum accumulation of these polysaccharides for 2 years of study was noted in the cultivars Bw 103, Maxima and Rocio [65].

When crossing high-glucan and high-yielding oat lines, a positive correlation was found in $\mathrm{F}_{4}$ hybrids grown at two points in Iowa between the content and viscosity of $\beta$-glucans, and the lines with high level of $\beta$-glucans, as a rule, were low-yielding. As among families, and among the lines within families, there were significant differences in most of the indicated traits. Consequently, targeted selection can increase the amount and viscosity of $\beta$-glucans in the grain in the cultivars being created [66], and the existing genotypic diversity of oats by $\beta$-glucan levels is sufficient for the progress in selection [67].

In intraspecific crossing, the content of grain $\beta$-glucans is inherited polygenically with the additive effect [68], does not depend so much on the place and growing conditions as the protein and oil content in grains, and does not correlate with the size of the grain itself [69-72]. The increase in the amount of $\beta$-glucans, on the one hand, is negatively associated with the amount of protein in gain [53], on the other hand, the increase is directly proportional to the rise in protein content and inversely proportional to fat level [73]. Apparently, the dynamics of accumulation of $\beta$-glucans in grains differs from that for other biochemical components [74].

Comparison of the $\beta$-glucan contents and other agronomical indicators in 9 barley and oat cultivars in the contrasting climatic conditions of Europe (at latitudes from Norway to Germany) revealed varietal differences in the range of 3.7-5.1 and 4.3-5.3\%, respectively. The influence of the ecological factor was 3.8-5.5 and 3.8-5.3\%, respectively. Warm and dry weather during the grainfilling period significantly increased the amount of $\beta$-glucan in oats [75].

The $\beta$-glucan content in grain of naked and hulled oats. In general, the average content of $\beta$-glucans varies from 3.1 to $4.5 \%$ for hulled grains and from 3.8 to $4.9 \%$ for naked grains [76]. During growing 10 oat cultivars for 3 years in the same place, the total content of dietary fiber, $\beta$-glucans and proteins was increased in the hulled genotypes compared to the naked genotypes [77]. The content of soluble $\beta$-glucans decreases from naked oats (3.91$7.47 \%$ ) to hulled oats (1.97-4.09\%), while insoluble $\beta$-glucans decreases from $13.79-33.73$ to $5.15-10.80 \%$ in reverse order. Histological examination of the grain showed that the amount of insoluble $\beta$-glucans falls in the direction from the outer covers to the endosperm [78].

In field examination of 11 samples of a naked oats (cv. Polar, the standard, and 5 lines) and hulled oats (cv. Bohun and 4 lines), it was noted that in naked forms the amount of grain fiber was lower than that in hulled ones, with a significantly higher protein and fat contents [79]. Naked and hulled cultivars grown in Italy for 2 years after a cereal precursor accumulated $9 \%$ more $\beta$ glucans than those cultivated after legumes. Bikini, Nave (Italy) and Abel (Czech Republic) cultivars were characterized by a high content of $\beta$-glucans 
among the naked genotypes, and Konradin cultivar accumulated the largest amount of dietary fiber. Naked samples are considered in connection with the production of dietary foods [80].

By computer modeling (the Monte Carlo method), the factors influencing the content of $\beta$-glucans in the hulled and naked oat cultivars were ranked. It turned out that the amount of $\beta$-glucans is mainly determined by the cultivar. The conditions of cultivation and the shelf life time adversely affected the analyzed indicator. The used model is proposed to be applied for evaluation of various agricultural technologies [81].

The study of the oat flakes, produced from 37 naked (China) and 44 hulled oats in the USA, Canada, New Zealand, Sweden, Denmark and the United Kingdom showed that in the first case the content of $\beta$-glucans and iron was significantly lower, and the water absorption rate at room temperature was higher. At the same time, an expert evaluation of the oat flakes from the naked samples was lower [82].

Quality and physiological role of $\beta$-glucans. It has already been noted that not only the content, but also the quality of the $\beta$-glucans determined, for example, by their viscosity and the functional activity is an important selection parameter. When comparing $1 \%$ water extracts of $\beta$-glucan in 5 lines of oats with an increased content of this polysaccharide (up to $7.8 \%$ against $4.4 \%$ in the usual Paul cultivar), significant varietal differences were revealed in rheological properties. These facts, as well as the difference in the viscosity as a function of the concentration, are explained by the unequal molecular weight [83]. In another study, 5 varieties of oats cultivated for 2 years in Norway were evaluated for the chemical composition and nutritional properties of the grain when fed to broiler chickens within 2 weeks. The studied samples differed significantly in nutritional value which negatively correlated with the content of dietary fibers [43].

In oats, the growth conditions significantly influenced on the viscosity of the flour suspension evaluated by a rotational viscometer, as well as on the extractability of $\beta$-glucans. At the same time, there was no significant dependence of extractability on the genotype. As for the chemical structure of the $\beta$-glucans, significant differences in polymerization of the molecules, due to both the genotype and cultivation conditions, were found. In the HiFi cultivar (USA) with a higher percentage of $\beta$-glucans, the molecules of this polymer were lower in the content of trisaccharides and higher in the proportion of tetrasaccharides compared to varieties that have an average content of $\beta$-glucans [12].

Relationship between the grain $\beta$-glucan content and other agronomic traits. The selection programs include creation of both high- and low-glucan oat lines. To separate the hybrid population into these contrasting groups, clear markers are needed. Thus, possible links of the content of $\beta$-glucans with various physical, morphological, physiological, agronomic and genetic-molecular signs of genotypes are studied.

As a non-destructive indirect method, a rapid assessment of the barley and oat grain for hulled or naked types [84] is proposed, which may be useful for predicting the content of dietary fiber.

In Scotland, when studying 33 cultivars of oats, it was shown that the correlation between the accumulation of $\beta$-glucans in grains and agronomic traits is usually absent or the obtained results are contradictory depending on the year or the cultivation conditions. In one of the breeding nurseries, a significant positive relationship was observed between the amount of $\beta$-glucans in grains and their full-scale weight, the protein content, the milling yield, and also the negative relationship of $\beta$-glucans and the date of tasseling. The authors optimis- 
tically concluded that simultaneous changes of these traits should not hamper the success of selection work, since the observed correlations are unstable [67]. A negative correlation between the content of $\beta$-glucans in oat grains and the total content of dietary fiber and crude fiber, as well as a positive correlation with the protein content (77) are described.

In Finland, comparison of $\beta$-glucans in 12 oat cultivars in eight points during 2 years revealed a significant positive correlation between the $\beta$-glucan content and grain yield, the vegetation period, grain weigh per volume (test weight), and the 1000 grain weight, as well as the significant negative correlation of the chemical index in question with the protein content and grain hull formation [76].

In the study of the 431 oat genotypes of the American Gene Bank by the genome-wide association study (GWAS) with determination of QTL for the content of $\beta$-glucans in grain, three independent markers closely associated with the target trait were found. Comparison of these data with the obtained results on rice showed that one of the markers located on the chromosome 7 of rice is associated with a family of $C s l F$ genes that are responsible for the synthesis of $\beta$ glucans in grain. In the future, such a study of the oat grsin can be successful in determining QTL for the markers of higher density [85].

Thus, the available data confirms the importance of $\beta$-glucans, the watersoluble dietary fibers, which have dietary, preventive and curative effects on the human body. Physicochemical properties, chemical modifications, and technological suitability open up clear prospects for the use of $\beta$-glucans in dietary food, medicines and cosmetics, and in these global industries $\beta$-glucans will play an ever-increasing role [86]. At the same time, the problem of reducing the amount of dietary fiber and the anti-nutritive properties of forage grain is topical in feed production. Under the joint Russian and international programs, the Vavilov AllRussian Institute of Plant Genetic Resources Currently conducts a comprehensive study of a large and diverse set of oat samples in order to reveal forms contrasting in $\beta$-glucan content for use in the dietary and feed sectors.

So, the development of functional food products from oat grain assumes the creation of highly productive cultivars with the maximum content and optimal chemical structure of $\beta$-glucans in combination with other quality parameters whereas the requirements are opposite for fodder cultivars. Insufficient knowledge and inconsistency of the available data hamper progress in these areas so far. Therefore, complex studies of the whole diversity of oat varieties are necessary to found contrasting parental plants and create cultivars for dietary and feed use.

\section{REFEREN CES}

1. B oczkowska M., Pody ma W., Łapiński B. Oat. In: Genetic and genomic resources for grain cereals improvement. Academic Press, 2016: 159-225.

2. Arendt E.K., Zannini E. Oats. In: Cereal grains for the food and beverage industries. Woodhead Publishing, 2013: 243-282.

3. Shewry P.R., Pi i ronen V., Lampi A.-M., Nyström L., Li L., Rakszegi M., Fraś A., Boros D., Gebruers K., Courtin C.M., Delcour J.A., Anders s o n A.A.M., D i m b e rg L., B e d ö Z., W a r d J.L. Phytochemical and fiber components in oat varieties in the HEALTHGRAIN Diversity Screen. Journal of Agricultural and Food Chemistry, 2008, 56 (21): 9777-9784.

4. W e l c h R.W. Nutrient composition and nutritional quality of oats and comparisons with other cereals. In: Oats: chemistry and technology. F.H. Webster, P.J. Wood (eds.). American Association of Cereal Chemists Inc., St. Paul, MN, USA, 2011: 95-107.

5. Ke ndall C.W.C., Es fahani A., David J.A., Je nkins D.J.A. The link between dietary fibre and human health. Food Hydrocolloids, 2010, 24(1): 42-48.

6. Ballabio C., Uberti F., Manferdelli S., Vacca E., Boggini G., Redae 1li R., Cat assi C., Li o netti E., P e c as E., Rest a n i P. Molecular characterisation of 36 oat varieties and in vitro assessment of their suitability for coeliacs' diet. Journal of Cereal 
Science, 2011, 54(1): 110-115.

7. Fin che r G.B., S t o n e B.A. Cell walls and their components in cereal grain technology. In: Advances in cereal science and technology. Y. Pomeranz (ed.). American Association of Cereal Chemists Inc., St. Paul, MN, USA, 1986: 207-295.

8. W o o d P.J., B e e r M.U. Functional oat products. In: Functional foods: Biochemical and processing aspects. G. Mazza (ed.). Technomic Publishing Co, Lancaster, PA, USA, 1998: 1-37.

9. W o o d P.J. Physicochemical characteristics and physiological properties of oat $(1 / 3),(1 / 4)-b-$ D-glucan. In: Oat bran. P.J. Wood (ed.). American Association of Cereal Chemists Inc., St. Paul, MN, USA, 1993: 83-112.

10. Mille r S.S., Fulcher R.G. Oat endosperm cell walls: II. Hot-water solubilization and enzymatic digestion of the wall. Cereal Chemistry, 1995, 72(2): 428-432.

11. Skendi A., Biliaderis C.G., Lazaridou A., Izydorczyk M.S. Structure and rheological properties of water soluble $\beta$-glucans from oat cultivars of Avena sativa and Avena bysantina. Journal of Cereal Science, 2003, 38(1): 15-31.

12. Do e h le rt D.C., S i m s e k S. Variation in $\beta$-glucan fine structure, extractability, and flour slurry viscosity in oats due to genotype and environment. Cereal Chemistry, 2012, 89(5): 242-246.

13. Johansson L., Tu o mainen P., Ylinen M., Ekholm P., Virkki L. Structural analysis of water-soluble and -insoluble $\beta$-glucans of whole-grain oats and barley. Carbohydrate Polymers, 2004, 58(3): 267-274.

14. Li W., Cu i S.W., Wang Q., Y a d a R.Y. Study of conformational properties of cereal $\beta$ glucans by computer modeling. Food Hydrocolloids, 2012, 26(2): 377-382.

15. Collins H.M., Burton R.A., Topping D.L., Liao M.-L., B a cic A., Finche r G.B. Variability in fine structures of noncellulosic cell wall polysaccharides from cereal grains: potential importance in human health and nutrition. Cereal Chemistry, 2010, 87(4): 272-282.

16. Li J.-M., Nie S.-P. The functional and nutritional aspects of hydrocolloids in foods. Food Hydrocolloids, 2016, 53(2): 46-61.

17. Ryu J.-H., Lee S., You S.G., Shim J.-H., Yoo S.-Ho. Effects of barley and oat $\beta$-glucan structures on their rheological and thermal characteristics. Carbohydrate Polymers, 2012, 89(4): 1238-1243.

18. AACC International Approved Methods of Analysis, 11th Ed. Method 32-22.01. Beta-Glucan in Oat Fractions and Unsweetened Oat Cereals. AACC International, St. Paul, MN, U.S.A, 1999.

19. Motilva M.-J., Serra A., Borrás X., Romero M.-P., Domínguez A., Labrador A., Peiry L. Adaptation of the standard enzymatic protocol (Megazyme method) to microplaque format for $\beta$ - $(1,3)(1,4)$-d-glucan determination in cereal based samples with a wide range of $\beta$ glucan content. Journal of Cereal Science, 2014, 59(2): 224-227.

20. $\mathrm{Munck}$ L. The revolutionary aspect of exploratory chemometric technology. Narayana Press, Gylling, Denmark, 2005.

21. B row n le e I.A. The physiological roles of dietary fibre. Food Hydrocolloids, 2011, 25(2): 238-250.

22. Petition for health claim: Barley betafiber and coronary heart disease. FDA - Food and Drug Administration. Office of Nutritional Products, Labeling and Dietary Supplements (hfs-800), 2006. Available http://www.fda.gov/ohrms/dockets/dockets/06p0393/06p-0393-cp00001-002-vol1.pdf. No date.

23. $\mathrm{H}$ a r l a nd J. Authorised EU health claims for barley and oat beta-glucans. In: Foods, nutrients and food ingredients with authorised EU health claims. Woodhead Publishing, 2014: 25-45.

24. Reyna-Villasmil N., Bermúdez-Pirela V., Mengual-Moreno E., Arias N., Cano-Ponce C., Le al-Gonzalez E., Souki A., Inglett G.E., Is raili Z.H., He rná nd e z-Her nánde z R., V a la s co M., A r raiz N. Oat-derived $\beta$-glucan significantly improves HDLC and diminishes LDLC and non-HDL cholesterol in overweight individuals with mild hypercholesterolemia. American Journal of Therapeutics, 2007, 14(2): 203-212.

25. Karmally W., Montez M.G., Palmas W., Martinez W., Branstetter A., R a makrishnan R., Holleran S.F., Haff ner S.M., G insberg H.N. Cholesterollowering benefits of oat-containing cereal in hispanic Americans. Journal of the American Dietetic Association, 2005, 105(6): 967-970.

26. R e gand A., Chowd hury Z., Tosh S.M., Wolever T.M.S., Wood P. The molecular weight, solubility and viscosity of oat beta-glucan affect human glycemic response by modifying starch digestibility. Food Chemistry, 2011, 129(2): 297-304.

27. Lafi a ndra D., Ri c c a rdi G., Shew ry P.R. Improving cereal grain carbohydrates for diet and health. Journal of Cereal Science, 2014, 59(2): 312-326.

28. Regand A., Chowdhury Z., Tosh S.M., Wolever T.M.S., Wood P. The molecular weight, solubility and viscosity of oat beta-glucan affect human glycemic response by modifying starch digestibility. Food Chemistry, 2011, 129(2): 297-304.

29. D o ng J., C a i F., S h e n R., Li u Y. Hypoglycaemic effects and inhibitory effect on intestinal disaccharidas of oat beta-glucan in streptozotocin-induced diabetic mice. Food Chemistry, 2011, 129(3): 1066-1071.

30. Tiwari U., Cum mins E. Meta-analysis of the effect of $\beta$-glucan intake on blood choles- 
terol and glucose levels. Nutrition, 2011, 27(10): 1008-1016.

31. W o o d P.J. Oat and rye $\beta$-glucan: properties and function. Cereal Chemistry, 2010, 87(4): $315-$ 330.

32. W o o d P.J. Cereal $\beta$-glucans in diet and health. Journal of Cereal Science, 2007, 46(3): 230-238.

33. Pentikäinen S., Karhunen L., Flander L., Katina K., Meynier A., Aymard P., Vinoy S., Poutanen K. Enrichment of biscuits and juice with oat $\beta$-glucan enhances postprandial satiety. Appetite, 2014, 75(4): 150-156.

34. Choromanska A., Kulbacka J., Re mbialkowska N., Pilat J., Oledzki R., $\mathrm{H}$ a ras y $\mathrm{m}$ J., S a c z k o J. Anticancer properties of low molecular weight oat beta-glucan An in vitro study. International Journal of Biological Macromolecules, 2015, 80(9): 23-28.

35. Parzonko A., Makarewicz-Wujec M., Jaszewska E., Harasym J., K o z ł ows k a -Woj c i e c hows k a M. Pro-apoptotic properties of $(1,3)(1,4)$ - $\beta$-d-glucan from Avena sativa on human melanoma HTB-140 cells in vitro. International Journal of Biological Macromolecules, 2015, 72(1): 757-763.

36. Błaszczyk K., Wi lczak J., Harasym J., Gudej S., Suchecka D., Krylikowski T., Lange E., Gromadzka-Ostrowska J. Impact of low and high molecular weight oat beta-glucan on oxidative stress and antioxidant defense in spleen of rats with LPS induced enteritis. Food Hydrocolloids, 2015, 51(10): 272-280.

37. Zhang G., H a make r B.R. Cereal carbohydrates and colon health. Cereal Chemistry, 2010, 87(4): 331-341.

38. D a v y B.M., Davy K.P., Ho R.C., B e ske S.D., D av rath L.R., M e lby C.L. Highfiber oat cereal compared with wheat cereal consumption favorably alters LDL-cholesterol subclass and particle numbers in middle-aged and older men. American Journal of Clinical Nutrition, 2002, 76(2): 351-358.

39. Delaney B., Nicolosi R.J., Wilson T.A., C arlson T., Frazer S., Zheng G.-H., Hess R., O st e rg re n K., Haw orth J., Knuts o n N. $\beta$-Glucan fractions from barley and oats are similarly antiatherogenic in hypercholesterolemic syrian golden hamsters. The Journal of Nutrition, 2003, 133(93): 468-475.

40. Chang H.-C., Chi en-Ning Huang C.-N., Y e h D.-M., Wang S.-J., Peng C.-H., $\mathrm{W}$ a ng C.-J. Oat prevents obesity and abdominal fat distribution, and improves liver function in humans. Plant Foods for Human Nutrition, 2013, 68(1): 18-23.

41. Gao C., Gao Z., Greenway F.L., Burton J.H., Johnson W.D., Ke e na n M.J., En right F.M., Martin R.J., Chu Y.F., Z he ng J. Oat consumption reduced intestinal fat deposition and improved health span in Caenorhabditis elegans model. Nutrition Research, 2015, 35(6): 834-843.

42. Faure A.M., Kop pe nol W.H., Nyström L. Iron(II) binding by cereal beta-glucan. Carbohydrate Polymers, 2015, 115(1): 739-743.

43. Svihus B., Gullord M. Effect of chemical content and physical characteristics on nutritional value of wheat, barley and oats for poultry. Animal Feed Science and Technology, 2002, 102(1-4): 71-92.

44. Toole G.A., Gall G.L., Colquhoun I.J., Drea S., O panowicz M., B ed Z., S h e w ry P.R., Mills E.N.C. Spectroscopic analysis of diversity in the spatial distribution of arabinoxylan structures in endosperm cell walls of cereal species in the HEALTHGRAIN diversity collection. Journal of Cereal Science, 2012, 56(2): 134-141.

45. Hurt H.D., Mathews R., Ink S.L. Biomedical considerations of oat dietary fiber and beta-glucans. Proc. 3rd Inter. Oat Confer. Lund, Sweden, 1988: 206-222.

46. S ong G., Hu o P., Wu B., Z hang Z. A genetic linkage map of hexaploid naked oat constructed with SSR markers. The Crop Journal, 2015, 3(2): 353-357.

47. Lafi a ndra D., Ri c c a rdi G., S h ew ry P.R. Improving cereal grain carbohydrates for diet and health. Journal of Cereal Science, 2014, 59(2): 312-326.

48. Sikora P., Tosh S.M., B rum me r Y., Ols s o n O. Identification of high $\beta$-glucan oat lines and localization and chemical characterization of their seed kernel $\beta$-glucans. Food Chemistry, 2013, 137(1-4): 83-91.

49. Chawade A., Sikora P., Brautigam M., Larson M., Vivekanand V., $\mathrm{N}$ a k a sh M.A., C h e n T., O ls s o n O. Development and characterization of an oat TILLING-population and identification of mutations in lignin and $\beta$-glucan biosynthesis genes. $B M C$ Plant Biology, 2010, 10(1): 86-99.

50. Redaelli R., Frate V.D., Bellato S., Terracciano G., Ciccoritti R., Ger$\mathrm{me}$ i e r C.U., S tefa $\mathrm{n}$ is E.D., S g ru $11 \mathrm{e} \mathrm{t}$ a D. Genetic and environmental variability in total and soluble $\beta$-glucan in European oat genotypes. Journal of Cereal Science, 2013, 57(2): 193-199.

51. Leggett J. M. Using and conserving Avena genetic resources. Proc. 5th Inter. Oat Confer. Saskatoon, Canada, 1996, v. I: 128-132.

52. How arth C., Cow a n A., Leggett J.M., Vale nt in e J. Using molecular mapping to access and understanding valuable traits in wild relatives of oats. Proc. 6th Inter. Oat Confer. Canterbury, New Zealand, 2000: 157-159. 
53. Mille r S.S., Wo od P.J., Pi etrzak L.N., Fulcher R.G. Mixed linkage beta-glucan, protein content and kernel weigh in Avena species. Cereal Chemistry, 1993, 70(2): 231-233.

54. Cho K.C., Whit e P.J. Enzymatic analysis of beta-glucan content in different oat genotypes. Cereal Chemistry, 1993, 70(5): 539-542.

55. F r e y K.J. Genetic resources of oats. In: Use of plant introductions in cultivar development. Crop Science Sosiety of America, Special publ. Part 1, 1991, 17: 15-24.

56. We lch R.W., Legget t J.M., Lloyd J.D. Variation in the kernel $(1,3)(1,4)$-beta-Dglucan content of oat cultivars and wild Avena species and its relationship to other characteristics. Journal of Cereal Science, 1991, 13(2): 173-178.

57. Loskutov I. Novel and traditional oat breeding directions. Proc. 32nd Nordic Cereal Congress. Espoo, Finland, 2015: 19.

58. Pet e r s o n D.M. Oat $\beta$-glucans and tocols. Proc. 4th Inter. Oat Conference. Adelaide, Australia, 1992, V. I: 19-24.

59. Peters on D.M. Oat - a multifunctional grain. Proc. 7th Inter. Oat Conference. Helsinki, Finland, 2004: 21-26.

60. Wood P.J., Pat on D., Siddiqui I.R. Determination of $\beta$-glucan in oats and barley. Cereal Chemistry, 1977, 54(3): 524-533.

61. S a l mi na I.S., Y a ros h N.P., Koval' L.A. Trudy po prikladnoi botanike, genetike $i$ selektsii, 1981, 70(3): 38-44 (in Russ.).

62. Loskutov I.G. Oves (Avena L.). Rasprostranenie, sistematika, evolyutsiya $i$ selektsionnaya tsennost' [Oats (Avena L.). Spread, taxonomy, evolution and selection value]. St. Petersburg, 2007 (in Russ.).

63. Loskutov I.G., Rines H.W. Avena L. In: Wild crop relatives: genomic \& breeding resources. V. 1. Cereals. C. Kole (ed.). Springer, Heidelberg, Berlin, NY, 2011: 109-184.

64. Ande rs o n A.A.M., B ö rjesd o t t e r D. Effects of environment and variety on content and molecular weight of $\beta$-glucan in oats. Journal of Cereal Science, 2011, 54(1): 122-128.

65. Martinez M.F., Are lovi ch H.M., We hrhahne L.N. Grain yield, nutrient content and lipid profile of oat genotypes grown in a semiarid environment. Field Crops Research, 2010, 116(1-2): 92-100.

66. Chernyshova A.A., White P.J., S cott M.P., Jannink J.-L. Selection for nutritional function and agronomic performance in oat. Crop Science, 2007, 47(9): 2330-2339.

67. Pet e rson D.M., Wes e nberg D.M., Burrup D.E. $\beta$-Glucan content and its relationship to agronomic characteristics in elite oat germplasm. Crop Science, 1995, 35(6): 965-970.

68. Holt haus J.F., Holla nd J.B., Whit e P.J., F rey K.J. Inheritance of $\beta$-glucan content of oat grain. Crop Science, 1996, 36(3): 567-572.

69. Brunner B.R., Freed R.D. Oat grain beta-glucan content as affected by nitrogen level, location and year. Crop Science, 1994, 34(2): 473-476.

70. Ga ns s mann W. Beta-glucan content in German oat cultivars and in oat bran obtained from them. Proc. 5th Inter. Oat Conference. Saskatoon, Canada, 1996, V. 2: 65-67.

71. M i 11 e r S.S., Vi n c e n t D.J., We is z J., F u l c he r R.G. Oat beta-glucans: an evaluation of eastern Canadian cultivars and unregistered lines. Canadian Journal of Plant Science, 1993, 73(3): 429-436.

72. P e t e rs o n D.M. Genotype and environment effects on oat beta-glucan concentration. Crop Science, 1991, 31(7): 1517-1520.

73. Kibite S., Edney M.J. The inheritance of beta-glucan concentration in an oat (Avena sativa L.) cross. Proc. 5th Inter. Oat Conference. Saskatoon, Canada, 1996, V. 2: 77-79.

74. C o x T.S., F r e y K.J. Complementarity of genes for high groat-protein percentage from Avena sativa L. and A. sterilis L. Crop Science, 1985, 25(1): 106-109.

75. Uhlen A.K., Holtekjølen A.K., Sahlstrøm S., Assveen M. Mixed linked $(1 \rightarrow 3)(1 \rightarrow 4) \beta$-D-glucans in barley and oat varieties grown in contrasting environments. Proc. 32nd Nordic Cereal Congress. Espoo, Finland, 2015: 56.

76. S a a s t a mo ine $\mathrm{n} \mathrm{M.,} \mathrm{Pla} \mathrm{a} \mathrm{mi} \mathrm{S.,} \mathrm{Ku} \mathrm{m} \mathrm{pula} \mathrm{i} \mathrm{ne} \mathrm{n} \mathrm{J.} \mathrm{Genetic} \mathrm{and} \mathrm{environmental} \mathrm{varia-}$ tion in $\beta$-glucan content of oats cultivated or tested in Finland. Journal of Cereal Science, 1992, 16(3): 279-290.

77. Havrlentová M., Bieliková M., Mendel L., Kraic J., Hozlár P. The correlation of (1-3)(1-4)- $\beta$-d-glucan with some qualitative parameters in the oat grain. Agriculture, 2008, 54(2): 65-71.

78. Gajdošová A., Petruláková Z., Havrlentová M., Červená V., Hozová B., Šturdík E., Kogan G. The content of water-soluble and water-insoluble $\beta$-d-glucans in selected oats and barley varieties. Carbohydrate Polymers, 2007, 70(1): 46-52.

79. B i e l W., B obko K., Macio rowski R. Chemical composition and nutritive value of husked and naked oats grain. Journal of Cereal Science, 2009, 49(3): 413-418.

80. Redaelli R., Sgrulletta D., Scalfati G., De Stefanis E., Cacciatori P. Naked oats for improving human nutrition: genetic and agronomic variability of grain bioactive components. Crop Science, 2009, 49(7): 1431-1437.

81. Tiwari U., Cummins E. Simulation of the factors affecting $\beta$-glucan levels during the 
cultivation of oats. Journal of Cereal Science, 2009, 50(2): 175-183.

82. Hu X.-Z., Z heng J.-M., Li X.-P., Xu C., Z h a o Q. Chemical composition and sensory characteristics of oat flakes: A comparative study of naked oat flakes from China and hulled oat flakes from western countries. Journal of Cereal Science, 2014, 60(2): 297-301.

83. Colleoni-Sirghie M., Kovalenko I.V., Briggs J.L., Fulton B., White P.J. Rheological and molecular properties of water soluble $(1,3)(1,4)-\beta$-d-glucans from high- $\beta$ glucan and traditional oat lines. Carbohydrate Polymers, 2003, 52(4): 439-447.

84. Polo nskiy V.I., Su mina A.V. Nondestructive methods for evaluating quality of grain in barley and oat genotypes. Proc. 32nd Nordic Cereal Congress. Espoo, Finland, 2015: 54.

85. N ewell M.A., A s o ro F.G., S c ott V.P., Wh it e P.J., B e a vis W.D., Jann in k J.-L. Genome-wide association study for oat (Avena sativa L.) beta-glucan concentration using germplasm of worldwide origin. Theor. Appl. Genet., 2012, 125: 1687-1696 (doi: 10.1007/s00122012-1945-0).

86. Zhu F., Du B., Xu B. A critical review on production and industrial applications of betaglucans. Food Hydrocolloids, 2016, 52(2): 275-288. 